\title{
Application of OLTT in gasification power systems
}

\author{
Brendan Quinlan ${ }^{1 *}$, Bear Kaufmann ${ }^{1}$, Giulio Allensina ${ }^{2}$, Simone Pedrazzi², Samuel Whipple ${ }^{1}$ \\ ${ }^{1}$ All Power Labs Inc., 1010 Murray Street, 94710 Berkeley, USA \\ ${ }^{2}$ BEE Lab (Bioenergy Efficiency Laboratory), Dept. of Engineering "Enzo Ferrari”, Via Vivarelli \\ 10/1, Modena 41125, Italy
}

Email: brendan@allpowerlabs.com

\begin{abstract}
A series of results obtained from a quasi-real-time analysis of tar concentration in small scale gasification systems is presented in this work. The instrument used to measure tar concentration is an online tar testing apparatus that was designed and built by the authors. Using the online tar testing apparatus enables phenomena to be observed that previously could not using standard methods. The influence of tar concentration due to four scenarios is presented using the online tar testing apparatus: dynamic behavior at different testing locations, impact as electrical output applied to the engine increases or decreases, impact of refueling events, and impact of different gasifier reactor architectures. Dynamic behavior of tar concentration was captured over all scenarios. Consistent results were obtained and results proved to be nonlinear and sometimes unpredictable.
\end{abstract}

Keywords: Biomass, Gasification, Syngas, Tar Testing, Light Absorbance.

\section{INTRODUCTION}

Tar testing is a fundamental technique for the evaluation of gasification systems. The gas (syngas) created from biomass gasification thermo-chemical processes contains organic compounds known as tars $[1,2]$. Tar content can drastically reduce the lifespan of several mechanical components due to fouling and corrosion [3]. When powering an engine with the gas, it is critical to control tar by means of filtration stages that effectively reduce the tar concentration entering the engine. A benchmark tar concentration is reported by Milne [2] where a maximum limit of $100 \mathrm{mg}$ tar/ $\mathrm{Nm}^{3}$ syngas is suggested for internal combustion use. A typical method for measuring tar concentration in syngas was developed by the IEA Bioenergy Task 33, US DOE and European Commission [4]. The tar sampling method is referred to as the standard method. The basic working principles of the standard method are: a known amount of syngas is scrubbed in isopropyl alcohol (IPA) with an impinger train, IPA is boiled and evaporated, and the remaining tar content is evaluated through gravimetric analysis. While this methodology is reliable, it requires long post-processing time to obtain tar concentration results and only an average tar concentration over typically an hour is reported. The necessity for a quick and continuous response was the primary driver for the development of online tar testing (OLTT) apparatus described by [5]. Previous work [5] focused on the development and validation of the colorimetry-based quasi- real-time tar tester. The present work investigates a series of tar concentration results obtained with the OLTT apparatus developed by [5]. The focus of the present work is to observe ability and application of the OLTT apparatus. The results presented would be impossible to obtain with the standard methodology.

\section{MATERIALS AND METHODS}

\subsection{Gasifier system and characteristics}

The gasification system used is an $18 \mathrm{~kW}$ All Power Labs Power Pallet [6] (Figure 1). Testing was performed at All Power Labs (APL), Berkeley, CA. The primary gasification reactor architecture that was used on the Power Pallet was an All Power Labs v5 downdraft reactor which is a single throat Imbert-style reactor. Another reactor type tested is an innovative reactor prototype. When testing the innovative design, remaining components of the gasification system (biomass feeding, gas filtration, engine and control) were identical. A flow diagram of the gasification system is shown in Figure 2. In the reactor, biomass is converted into syngas. Approximately $5 \%$ of the dry biomass is converted into biochar. The syngas passes through a cyclone for fine particulate filtration. The syngas is cooled in a tube and shell heat exchanger with atmospheric air. The syngas is filtered to remove any remaining particulate and tar. The syngas is 
mixed with warmed air from the tube and shell heat exchanger and combusted in an internal combustion engine for electrical power generation.

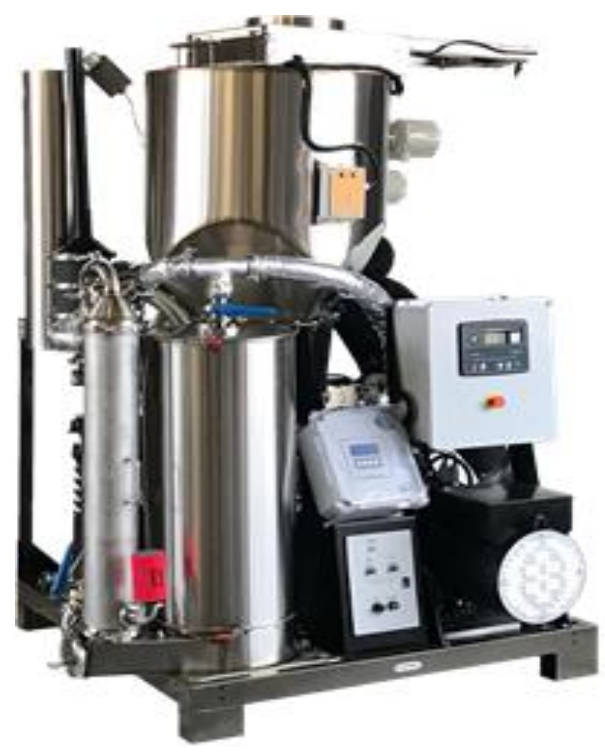

Figure 1. All Power Labs PP20 system

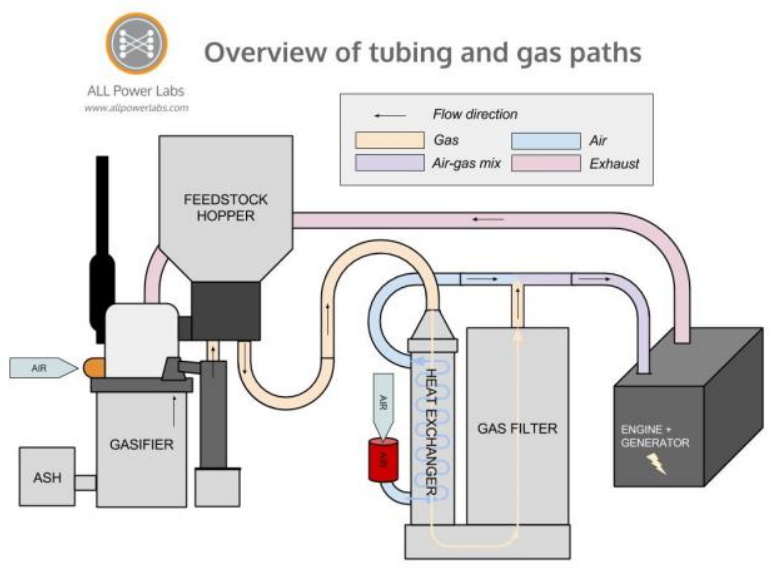

Figure 2. All Power Labs PP20 flow diagram

\subsection{Downdraft reactors}

The v5 All Power Labs downdraft gasifier is depicted in Figure 3.

A detailed description of the gasification reaction in the v5 is given. The biomass is delivered by the fuel auger to the top of the reactor and is pyrolyzed in the pyrolysis stage (3). Heat from exhaust gases is used to induce pyrolysis in the pyrolysis stage via a heat exchanger. The pyrolyzed biomass reacts with hot air that enters in the reactor through air nozzles (4) and creates a combustion zone (7) where the pyrolysis tars are combusted. The hot gases produced in the combustion zone react with the carbon in the reduction zone (8) create fuel gases such as $\mathrm{CO}, \mathrm{H}_{2}$ and $\mathrm{CH}_{4}$. The char that does not react with combustion gases is pushed out of the reactor as biochar by means of an ash auger (9). Syngas is created at this point in the reactor. The syngas travels up through a passage (6) between the outside wall of the reactor and the inside pyrolysis and combustion zones. Heat exchange occurs with the intake air for the gasification reaction and the outgoing syngas. Reactor pressure is monitored through a port at the top of the reactor (1). The port at the top of the reactor extends through the pyrolysis zone (2) to a location just above the air lines. An innovative reactor was developed and tested in 2016 at APL that aims to dramatically improve tar cracking and conversion to syngas while running with non-ideal fuels like wood chips fines or crushed walnut shell fines, and other important agricultural and forestry byproducts. A reactor able to operate on these fuels would be significant for gasification [7].

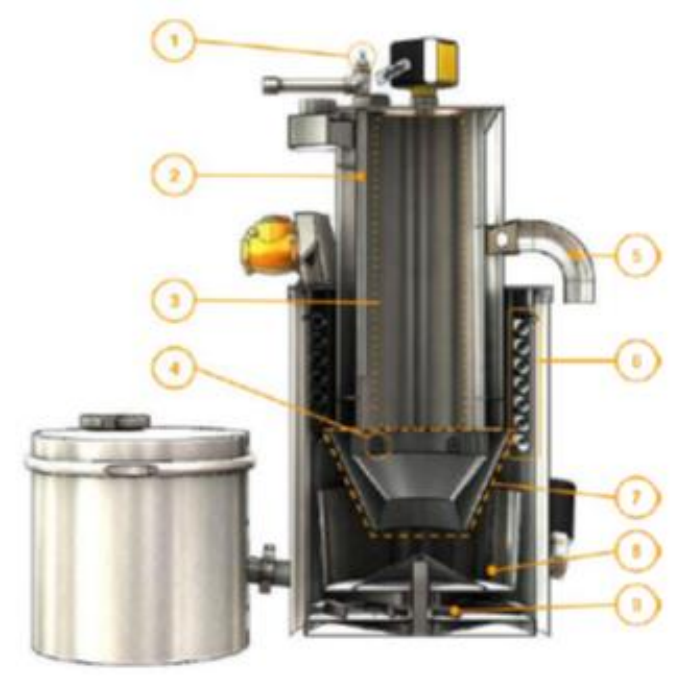

Figure 3. All Power Labs PP20 downdraft gasifier

\subsection{On-line tar testing apparatus}

The OLTT apparatus is divided into three sub-systems: scrubber sub-system, colorimetry sub-system, and flow measurements/control sub-system. Details of the system are reported in previous work [5].

The scrubber sub-system has two purposes: it provides particulate matter filtration of the syngas and scrubs all tars from the syngas into the IPA/tar mixture. The colorimetry sub-system extracts the IPA/tar mixture from the scrubber sub-system and collects absorbance data by passing the solution through a colorimeter. Tar concentration are calculated by following the procedure developed in [5].

The flow measurements/control sub-system controls and measures the flow of syngas through the apparatus. It is composed by a dry gas meter, rotameter, and rotary vane gas pump. The OLTT apparatus is shown in Figure 4. A general description of the components of the OLTT apparatus is provided:

A. Heated extraction tube and heated thimble filter maintained at $300{ }^{\circ} \mathrm{C}$ to prevent the gas condensation.

B. Mixing chamber for IPA and syngas.

C. Main scrubber and separator. Here the tar is scrubbed out of the gas creating two separate phases: an IPAtar solution and clean syngas.

D. Capacitive sensor for control of the peristaltic pump. This allows the amount of tar-IPA solution constant in the scrubber, and sending the excess to the colorimeter.

E. Syringe filter, for final particulate removal (over 0.2 microns).

F. LED-powered colorimeter. It measures absorbance used as basis for tar concentration evaluation.

G. Storage flask for the tar-IPA solution for further standard gravimetric analysis.

H. Fresh $99.5 \%$ IPA storage flask. 
I. Peristaltic pump for metering and moving the IPA from the storage flask to the mixing chamber.

J. Measuring rotameter for real-time syngas flow rate through the OLTT system.

K. Dry gas meter for measuring syngas total volume used in every OLTT run.

L. Syngas pump. It provides a gas stream to the OLTT system, and it then sends the gas back into the gasification system.

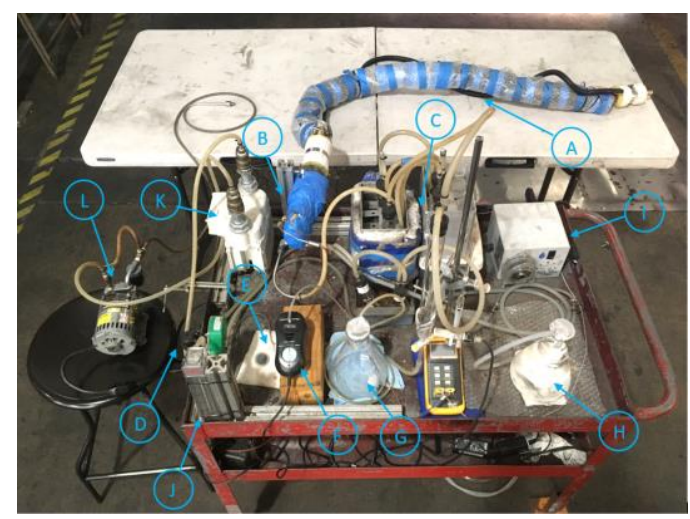

Figure 4. Photograph of the online tar testing apparatus

\subsection{Test scenarios}

The scenarios chosen to investigate where the impact as electrical output from the engine increases or decreases, impact of refueling events, dynamic behavior at different testing locations, and impact of different gasifier reactor architectures. The term scenario refers to a procedure for testing. The term test refers to individual tar tests that were performed with the OLTT apparatus.
The first scenario was executed by adjusting the electrical output of the engine. Three tests were performed in order to capture repeatable results. All parameters such as test equipment (PP 1076), gasifier architecture (v5), filter type (s1.1), fuel type (wood chips), and engine type (GM vortec $3.0 \mathrm{~L})$ were held constant throughout tests 1 - 5. The procedure for tests 1 - 5 was the same and as follows: after at least one hour of machine operation prior to testing connect the OLTT to the machine, after one hour of testing change the electrical output, after at least 7 minutes from adjusting the electrical output or connecting refuel the machine, after two hours of testing disconnect the OLTT.

The second scenario was executed by refueling at specific times. The fuel is added as a batch process by filling the 300 liter hopper during machine operation. The fuel is delivered into the reactor by means of a fuel auger which is automatically controlled by a level switch. Refueling events occurred during tests $1-5$. All parameters were held constant throughout tests $1-5$. The procedure for tests $1-5$ is described above.

The third scenario was executed by performing testing at a different location. Two test locations were chosen: post cyclone and post filter. Tests 1 - 5 were performed at the post filter location. Tests 6 and 7 were performed at the post cyclone location. The procedure for test 6 is as follows: after at least one hour of machine operation prior to testing connect the OLTT to the machine, after one hour of testing disconnect the OLTT.

The fourth scenario was executed by performing testing on a different gasification reactor type. All other parameters are the same as test 6 except for the gasifier architecture. The procedure for test 7 is as follows: after at least two hours of machine operation prior to testing connect the OLTT to the machine, after two hours disconnect the OLTT.

Table 1 is a summary of all the scenarios, tests, and corresponding key test parameters that were investigated.

Table 1. Summary of key test parameter

\begin{tabular}{|c|c|c|c|c|c|c|c|}
\hline & \multicolumn{5}{|c|}{ Scenarios 1 and 2} & \multirow{2}{*}{$\frac{\text { Scenario } 3}{\text { Test } 6}$} & \multirow{2}{*}{$\frac{\text { Scenario } 4}{\text { Test } 7}$} \\
\hline & Test 1 & Test 2 & Test 3 & Test 4 & Test 5 & & \\
\hline $5 \mathrm{~kW}$ & & & & $\mathrm{x}$ & $\mathrm{x}$ & & \\
\hline $10 \mathrm{~kW}$ & $\mathrm{x}$ & $\mathrm{x}$ & $\mathrm{x}$ & & & $\mathrm{x}$ & $\mathrm{x}$ \\
\hline $16 \mathrm{~kW}$ & $\mathrm{x}$ & $\mathrm{x}$ & $\mathrm{x}$ & & & & \\
\hline $18 \mathrm{~kW}$ & & & & $\mathrm{x}$ & $\mathrm{x}$ & & \\
\hline Post Cyclone & & & & & & $\mathrm{x}$ & $\mathrm{x}$ \\
\hline Post Filter & $\mathrm{x}$ & $\mathrm{x}$ & $\mathrm{x}$ & $\mathrm{x}$ & $\mathrm{x}$ & & \\
\hline Wood chips & $\mathrm{x}$ & $\mathrm{x}$ & $\mathrm{x}$ & $\mathrm{x}$ & $\mathrm{x}$ & $\mathrm{x}$ & \\
\hline Walnut shell fines & & & & & & & $\mathrm{x}$ \\
\hline V5 Reactor & $\mathrm{x}$ & $\mathrm{x}$ & $\mathrm{x}$ & $\mathrm{x}$ & $\mathrm{x}$ & $\mathrm{x}$ & \\
\hline Innovative Reactor & & & & & & & $\mathrm{x}$ \\
\hline $\begin{array}{c}\text { Average Tar } \\
\text { Concentration } \\
{\left[\mathrm{mg} / \mathrm{Nm}^{3}\right](\text { load } \mathrm{kW})}\end{array}$ & $\begin{array}{l}104(10) \\
135(16)\end{array}$ & $\begin{array}{l}69(10) \\
165(16)\end{array}$ & $\begin{array}{l}108(10) \\
140(16)\end{array}$ & $\begin{array}{l}279(5) \\
353(18)\end{array}$ & $\begin{array}{l}238(5) \\
249(18)\end{array}$ & $491(10)$ & $63(10)$ \\
\hline
\end{tabular}




\section{RESULTS AND DISCUSSION}

\subsection{Electrical output increase and decrease}

The impact of increasing the electrical output of the Power Pallet from approximately $10 \mathrm{~kW}$ to $16 \mathrm{~kW}$ is shown in Figures 5, 6, and 7 .

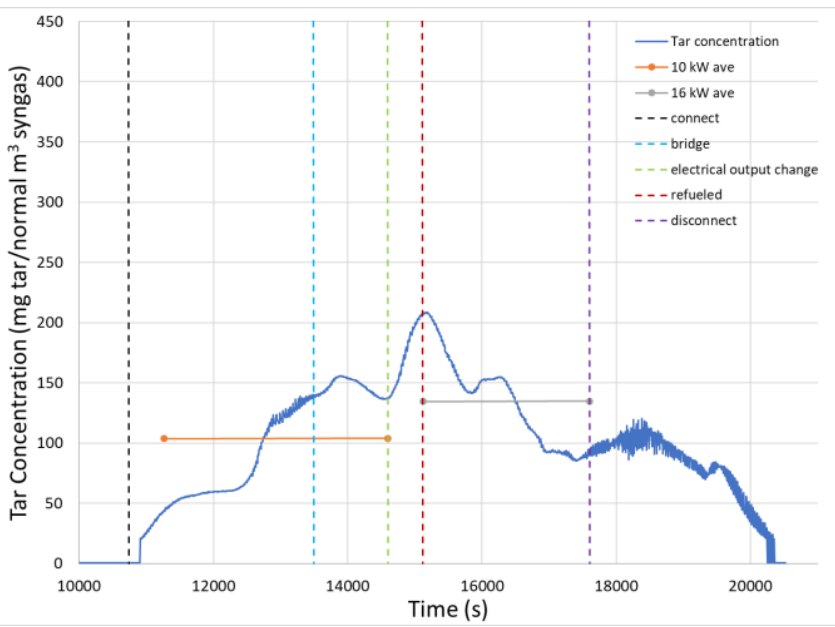

Figure 5. Test 1 response

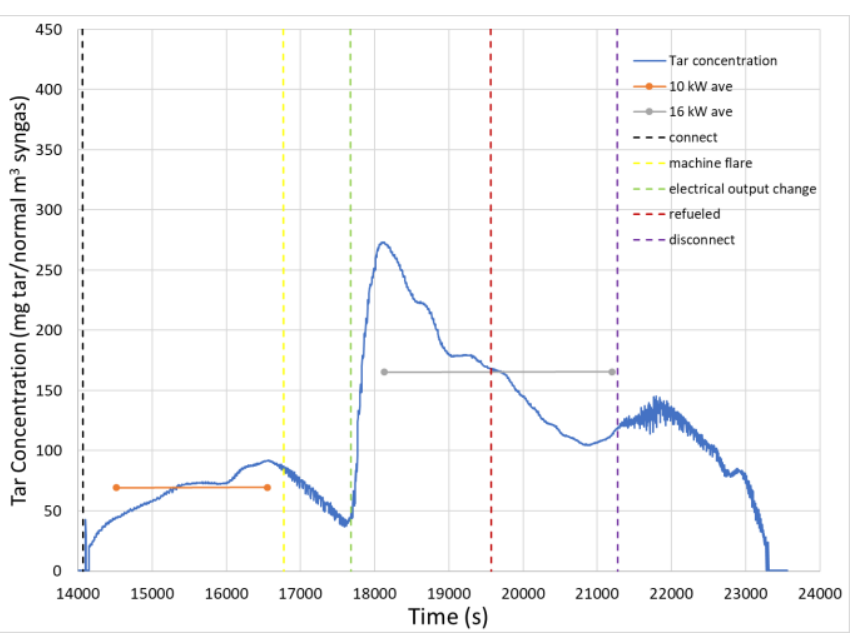

Figure 6. Test 2 response

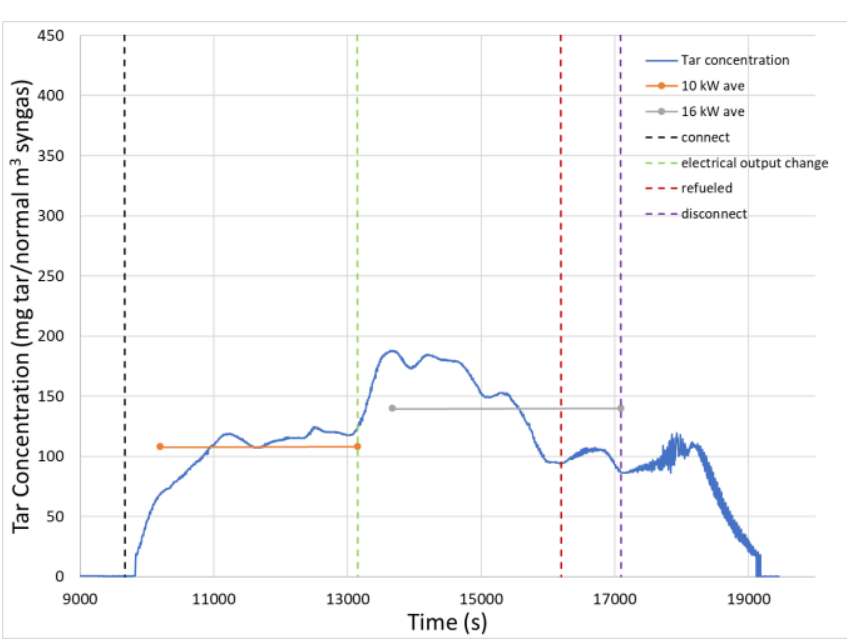

Figure 7. Test 3 response
The responses show an initial tar concentration increase with the increase in power output. However, approximately mid-way through the $16 \mathrm{~kW}$ sample period a sudden decrease in tar concentration occurs. This happens for all cases.

One possible explanation for this behavior is the shorter gas residence time in the reduction zone of the gasifier. In this zone, the tar compounds react with the hot charcoal to generate syngas. When the electrical output is increased, demand for syngas by the internal combustion engine increases. This induces a transition period for thermochemical reactions in the reactor to reach a new equilibrium. As a result of the transition period, tar concentrations momentarily increase and then decrease.

An alternate explanation for the behavior is that higher electrical output result in higher gas velocity through the filter which degrades the filter efficiency. The standard filter uses charcoal as filtering media. The charcoal is porous and it is able to adsorb tars and water droplets in the gas stream. If the gas velocity is too high, the adsorption of tar becomes less effective. The peak tar concentration may be a consequence of the increased syngas velocity in the filter desorb or entrain a consequential amount of condensed tars.

The impact of decreasing the electrical output from $18 \mathrm{~kW}$ to $5 \mathrm{~kW}$ during machine operation is shown in Figures 8 and 9.

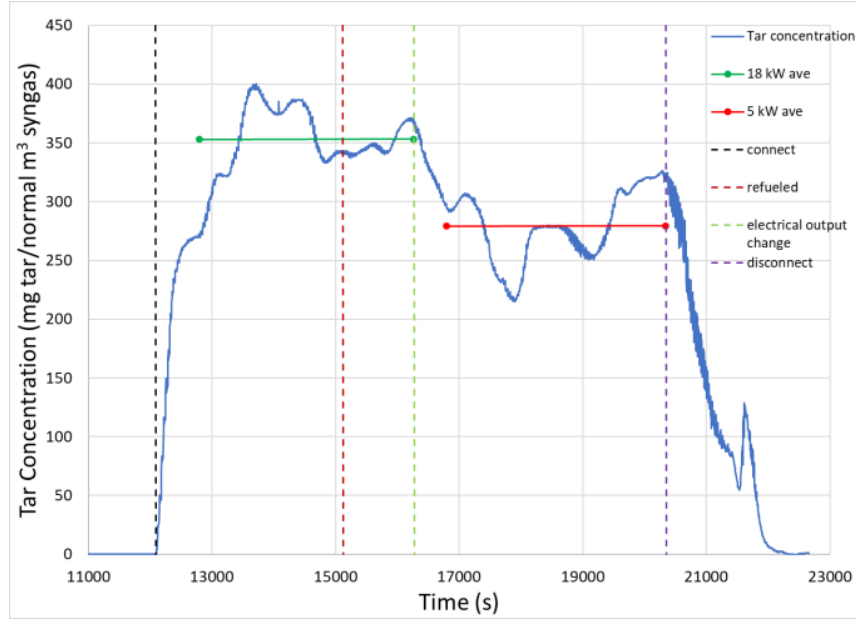

Figure 8. Test 4 response

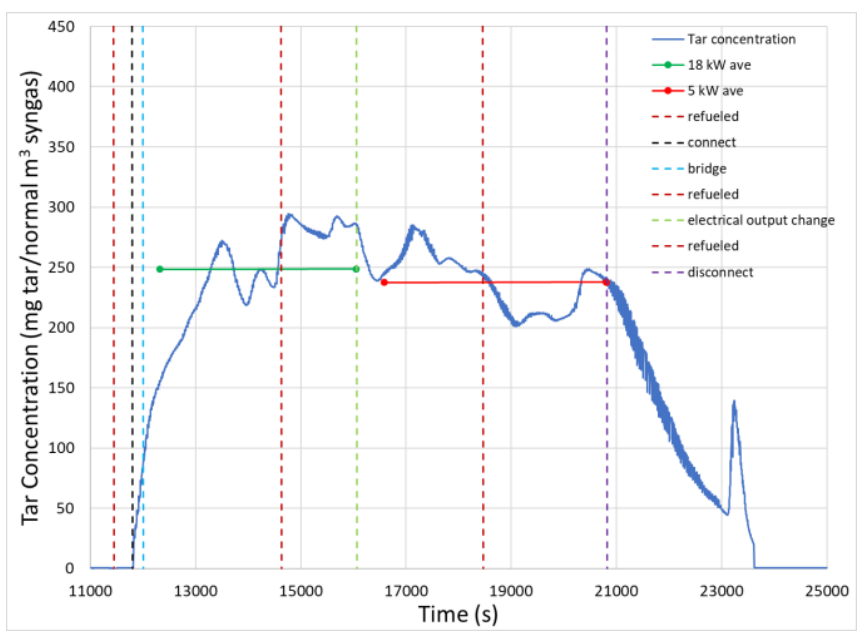

Figure 9. Test 5 response 
The response shows higher tar concentration for $18 \mathrm{~kW}$ as opposed to $5 \mathrm{~kW}$. While Figures 8 and 9 are noisy, Figure 8 shows a relatively rapid response to the changed load which are indicative of the measurement system response capabilities. Historically, the index "turndown ratio" [8] has been used and represents the ratio of minimum power to the maximum achievable power for an engine fueled with syngas and operated continuously. The minimum and maximum loads are significantly impacted by the gas quality output of a gasifier, of which tar is a significant factor. The average tar concentrations over loads are shown in Table 2 Where $n$ is the number of test at each respective power output level:

Table 2. Average tar concentration

\begin{tabular}{|c|c|c|c|c|}
\hline Output $[\mathrm{kW}]$ & 5 & 10 & 16 & 18 \\
\hline $\begin{array}{c}\text { Average Tar } \\
\text { Concentration } \\
{\left[\mathrm{mg} / \mathrm{Nm}^{3}\right]}\end{array}$ & 260 & 90 & 150 & 300 \\
\hline $\mathrm{n}$ & 2 & 3 & 3 & 2 \\
\hline
\end{tabular}

This behavior is possibly a result of the thermochemical equilibrium of gasification. At electrical outputs of 18 and 5 $\mathrm{kW}$ the reactor is operating at a higher and lower extreme. At $18 \mathrm{~kW}$ the residence time of pyrolysis gases through the reactor is too short. This results in higher tar concentrations due to incomplete cracking of tar. At $5 \mathrm{~kW}$ the reactor is operating at a lower limit and the reactions of gasification occur at lower temperature where the tar thermal cracking is reduced.

\subsection{Pre and post filtration analysis}

A comparison between Figure 5 - 7 and Figure 10 outlines the difference of the gas quality before and after filtration.

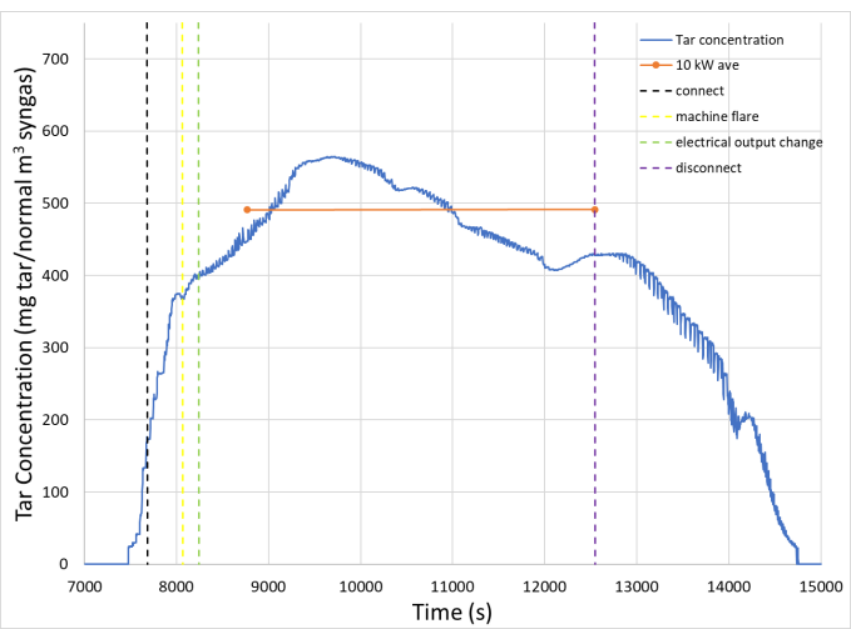

Figure 10. Test 6 response

The first result that can be obtained for comparison from Figure 10 is an average tar concentration for both testing locations. At the post cyclone location an average tar concentration of $491 \mathrm{mg} \operatorname{tar} / \mathrm{Nm}^{3}$ syngas was found. At the post filter location, an average tar concentration of $94 \mathrm{mg}$ $\operatorname{tar} / \mathrm{Nm}^{3}$ syngas was found. The average tar concentrations at the post filter location are lower than the average tar concentrations at the post cyclone locations. This is expected seeing as how the filter is intended to lower the tar concentration in the syngas.

The OLTT allows the dynamic response of the gasification system to be observed at the desired test location. Comparing Figures $5-7$ to Figure 10 it is shown that the response is noisier at the post filter location as opposed to the post cyclone location. One possible explanation for this behavior is the gas flow through the filter is variable due to gas quality changes with velocities varying erratically. This would cause sharp increases and decreases in tar concentration.

Another explanation of this behavior is explained by the filtration design. The filter is a packed bed filter using wetted charcoal media. When a gas stream passes through it, different gas temperatures and relative humidity leads to the adsorption and desorption of different species from the filter media as conditions change.

\subsection{Effects of refueling events}

Manual refueling events are shown in Figures 5 - 9 and are marked by a dark red dashed vertical line. In all figures a change in tar concentration is present immediately after refueling. In Figures 5, 6, and 9 tar concentration decreases where as in Figures 6 and 7 tar concentration increases.

A possible explanation for this divergent behavior is that opening the hopper lid allows air to flow into the reactor from two different paths: the airlines and the hopper. This new pathway for air would carry an increased amount of pyrolysis vapour from the pyrolysis zone of the reactor down into the combustion zone. If the refueling process takes additional time than normal, the combustion zone may rise into the pyrolysis zone by a few centimeters due to the presence of oxygen in the pyrolysis zone. This explanation would explain the random behavior of refueling events and would greatly depend on the amount of time required to refuel the machine. Refueling time was not recorded for the present work.

\subsection{Effects of reactor architecture}

Figure 11 shows the response of tar concentration from an innovative reactor design.

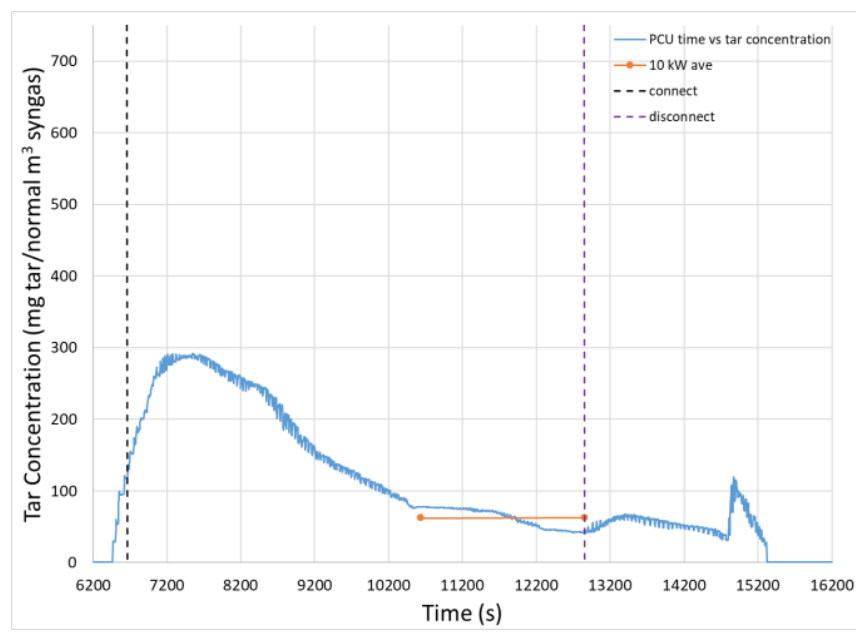

Figure 11. Test 7 response

The response shown in Figure 11 begins with a spike in tar concentration over the first 2000 seconds of sample time. After 2000 seconds the tar concentration begins to decline 
over roughly 3000 seconds. After approximately 5000 seconds of sample time the tar concentration reaches a quasisteady state.

Significant differences are present when comparing the dynamic response of the innovative reactor design shown in Figure 11 to the v5 reactor shown in Figure 10. For instance, the innovative reactor spikes in tar and shows an exponential decline over 3000 seconds whereas the v5 reactor rises in tar and comes to a quasi-steady state. The innovative reactor and the v5 responses seem to match an impulse and step input, respectively, which would indicate major differences in reactor dynamics. The average tar concentrations for the innovative design and the v5 are $63 \mathrm{mg}$ tar $/ \mathrm{Nm}^{3}$ syngas and $491 \mathrm{mg} \operatorname{tar} / \mathrm{Nm}^{3}$ syngas respectively. A lower tar concentration is evidence of a more effective tar cracking reactor design.

\section{CONCLUSIONS}

Tar concentration in gasification systems changes rapidly and sometimes unpredictably. Tar testing with standard methods have no ability to capture fluctuations in tar concentration. However, the OLTT apparatus used in the present work effectively captures fluctuations in tar concentration. Dynamic effects of events and changes in testing parameters such as altering the electrical output, refueling, testing location, and reactor architecture are now visible and can be understood in greater detail. Several conclusions may be drawn from the present work:

1. The OLTT apparatus is capable of capturing dynamics in tar concentration.

2. Consistent results are obtained from the OLTT apparatus shown in Figures 5 - 10.

3. Events such as altering the electrical output, refueling, testing location, and reactor architecture influence tar concentration in nonlinear and sometimes unpredictable ways.

The development and application of the OLTT apparatus has opened new potential for further research.

1. Development of theoretical models to predict the influence of events and test parameters.

2. Better testing resolution to capture the influence of events that occur rapidly.

3. A larger data set of results for better statistical averages and comparison between dynamic events.

\section{REFERENCES}

[1] Basu P. (2013). Biomass gasification, pyrolysis and Torre faction, Elsevier.

[2] Milne T.A., Evans R.J., Abatzoglou N. (1998). Biomass gasifier tars: Their nature, formation, and conversion, National Renawable Energy Laboratory, Cole Boulevard Golden, Colorado, NREL/TP-57025357.

[3] Knoef H.A.M. (2005). Handbook of Biomass Gasification 2ed, BTG, Enschede, The Netherlands.

[4] Biomass gasification - Tar and particles in product gases (2006). CSN P CEN/TS 15439.

[5] Brendan Q., Kaufman B., Allesina G., Pedrazzi S., Hasty J., Puglia M., Morselli N., Tartarini P. (2017). The use of on-line colorimetry for tar content evaluation in gasification systems, International Journal of Heat and Technology, Vol. 35, Special Issue 1, September 2017, pp. S145-S151. DOI: 10.18250/ijht.35Sp0120

[6] All power labs official website, from www.allpowerlabs.com accessed $28 \mathrm{Mar}, 2017$

[7] Allesina G., Pedrazzi S., Sgarbi F., Pompeo E., Roberti C., Cristiano V., Tartarini P. (2015). Approaching sustainable development through energy management, the case of Fongo Tongo, Cameroon, International Journal of Energy and Environmental Engineering, Vol. 6, No. 2, pp. 121-127. DOI: 10.1007/s40095-014-0156-7

[8] Reed T.B., Das A. (1988). Handbook of Biomass Downdraft Gasifier Engine Systems, U.S. Department of Energy: Solar Energy Research Institute.

[9] FAO. (1986). Wood gas as engine fuel, Food and Agriculture of the United Nations, Rome, ISBN 92-5102436-7.

[10] Pedrazzi S., Allesina G., Tartarini P. (2012). Aige conference: A kinetic model for a stratified downdraft gasifier, International Journal of Heat and Technology, Vol. 30, No. 1, pp. 41-44.

[11] Allesina G., Pedrazzi S., Tartarini P. (2013). Modeling and investigation of the channeling phenomenon in downdraft stratified gasifiers, Bioresource Technology, Vol. 146, pp. 704-712. DOI: $\underline{10.1016 / \text { j.biortech.2013.07.132 }}$ 